Emir. J. Agric. Sci. 2004. 16 (1) : 08-14

http://www.cfs.uaeu.ac.ae/research/ejas.html

\title{
A southern african survey conducted for off-types on date palms produced using somatic embryogenesis
}

\author{
M. J. McCubbin ${ }^{1}$, A. Zaid ${ }^{2}$, J. Van $\operatorname{Staden}^{3}$ \\ ${ }^{1}$ Pasture Valley (Pty) Ltd., P.O. Box 86, Nhlangano, Swaziland \\ ${ }^{2}$ Date Palm Research and Development Project (UAE/2000/002), United Nations \\ Development Program (UNDP / UNOPS), UAE University, P.O. Box. 81908, Al Ain, UAE \\ ${ }^{3}$ Research Centre for Plant Growth and Development, University of Natal, Private \\ Bag X01, Scottsville, 3201, Republic of South Africa
}

\begin{abstract}
A survey was conducted in the Republic of South Africa, Namibia and Zimbabwe on offtypes of date palms produced using somatic embryogenesis. Off-types reported included leaf variegation, compact growth, seedless fruits, a low pollination percentage in one variety and leaf and spine structure variations. Possible explanations include environmental and physiological factors, human error and somaclonal variation due to tissue culture processes.
\end{abstract}

Keywards: Date palm, Phoenix dactylifera, somaclonal variation, somatic embryogenesis, tissue culture, off-types.

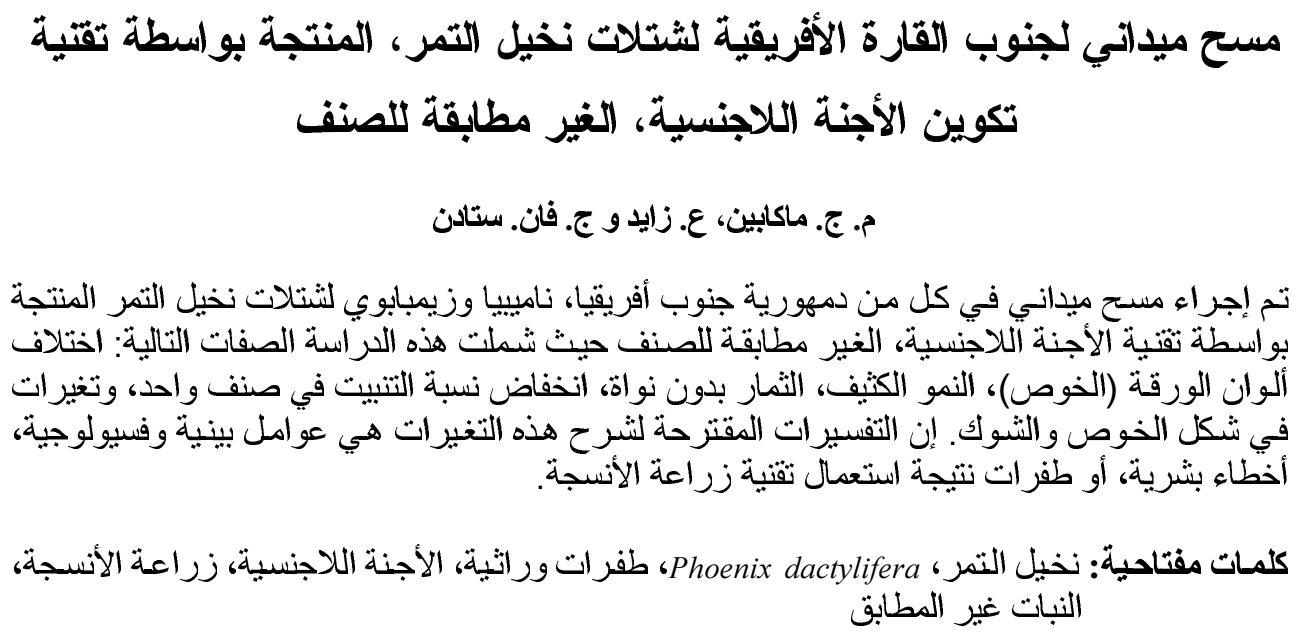

\section{Introduction}

Date palms (Phoenix dactylifera L.) were introduced to Southern Africa from seeds brought in by missionaries initially, until the first commercial plantings were made using off-shoots purchased from Yuma, United States of America (Niemoller, personal communication). Tissue cultured plants for commercial plantings in southern Africa have only been introduced about a decade ago and the plantings are still very young. However, because propagation by tissue culture allows for the transportation of a relatively diseasefree plant area, and true- to-typeness along with numerous other advantages, the purchasing of such plants has become popular.

Tissue cultured date palms are normally produced using 2 techniques: organogenesis and somatic embryogenesis (direct and indirect). Direct somatic embryogenesis of date palms involves the proliferation of embryo cultures rather than callus cultures used in the indirect somatic embryogenesis technique. Since most plants in southern Africa originated from plants produced via somatic embryogenesis, the author will concentrate on the latter.

The initiation phase of this technique is normally done by the introduction of high concentrations of the auxin 2,4-D 
with/without other plant growth regulators or combinations of other auxins and cytokinins such as NAA, NOA, GA and 2$\mathrm{iP}$ into the plant growth medium of the explant. This induces callus and embryo development, which in turn allows for the mass production of plantlets. The dedifferentiated cells grow in an unorganized mass. Should somaclonal variation occur at this stage, cells thought to be genetically identical turn out to be dissimilar varying in height, colour, shape, disease resistance, and yield and maturation characteristics (Evans, 1989). This somaclonal variation has been reported in more than 30 species, including wheat, maize, tomato, banana, oil palm and potato. These spontaneous genetic changes occur in traits under simple genetic control, such as grain colour in wheat to those under polygenic control such as plant height (Miller, 1985).

Off-types, often referred to as "mutations," are a controversial issue among tissue culture laboratories and the purchaser of such plants. When plants show abnormal plant growth behaviour it is important to determine whether such abnormality is a result of environmental conditions or genetic aberrations somatic cell mutants with altered or arrested embryo phenotypes have previously been described (Terzi and Loschiavo, 1990). In most cases the genes affected have not yet been identified, so although plant embryogenesis is morphologically well described, our understanding of the molecular events that generate the plant embryo and its development is still very limited.

Abnormalities in plant growth with the use of 2,4-D on plants has been previously reported (Loubser, 1980). Unlike various other plant growth regulators such as IAA, which is broken down by the plant once absorbed, 2,4-D is sequested by the plant, not broken down and is continually recycled. It has also been found that the 2,4-D effect is cumulative and because it remains in the tissues of the plants for long periods, the effects are long lasting (Loubser, 1980).

With the induction of date palm callus by using high concentrations of auxin 2,4- D, the risk increases that plantlets regenerated from such a process by embryogenesis may not be true-to-type. In a commercial set up where thousands of plantlets are generated from a single explant, stability is critical. Should an off-type occur that affects, for example, the fruit in any form, it will only be noticed 4 years after purchase from the laboratory whereby the plant has subsequently incurred substantial development costs.

To be able to assess the genetic stability of in vitro derived clones becomes essential in the application of biotechnology for micropropagation of true-to-type clones, for in vitro germplasm conservation and for commercial planting of high quality materials. For example, cytological studies of palm cell cultures are few and even these are briefly reported. It would seem useful, particularly in view of the commercial potential of the date palm to build up an understanding of their chromosomal cytology in relation to such factors, such as clonal origin, growth rates, capacity for differentiation and media components, especially growth regulators. The value of the cytological studies would, however, be limited by their failure to detect changes at the molecular level (Paranjothy, 1982).

Molecular studies distinguishing between varieties and the isolation of minicircular plasmid like DNA's have been conducted (Benslimane et al. 1994). An Rflp analysis of five date palm elite cultivars (Barhee, Deglet Nour, Khalassa, Khadrawy and Medjool) has been performed on offshoot leaves surrounding the shoot tips used to initiate tissue culture (Corniquel and Mercier, 1994). AL-Shayji et al. (1994) isolated and analysed total genomic DNA from the date palm in order to assist in genetic improvement of the varieties as well. These techniques will assist in comparisons against a known variety. An off-type in a 
block of Medjools for example, can be tested using these techniques to distinguish whether mislabelling may have been the cause of a date palm dissimilar to those around it. The technique also provides a guideline against which off-types can be compared to known varieties.

A satisfactory process for the regeneration of date palm elite cultivars should result in individuals phenotypically and genetically identical to the explant from which they are derived. However, due to somaclonal variation generated during in vitro culture, it cannot be certified that the genetic organization of tissue culture-derived material is identical to the mother plant or explant and that it is inherently homogeneous (Evans, 1989). The aim of this study was, therefore, to find and identify off-types of date palms by means of a survey conducted in the Southern African region which had previously not been reported.

\section{Materials and Methods}

A survey was issued to over 30 date palm farmers and companies in Southern Africa in March 1999. The farmers were randomly selected ensuring a good representation from each growing area, i.e. Northern Cape, Limpopo Province in the Republic of South Africa, growers from Namibia and a single farmer from Zimbabwe (there is only one commercial grower of date palms in Zimbabwe). The same written questionnaire was used for companies and farmers alike.

The questionnaire dealt with the origins of the date palms and any abnormalities that had been observed. Typical questions asked were: Name and contact details, list variety, number and year of date palms planted, which laboratory or laboratories supplied the plants, were plants embryogenic or organogenic in origin, did you notice any abnormalities in your plants. If the answer is Yes, then describe the abnormality and number of plants affected. How soon after planting did you notice the abnormality?
Each anomaly was recorded and a follow up discussion initiated with the farmer by telephon on the details of the anomaly. For example, the incidence of disease, nutrient application and pollination and irrigation practices used on the farm were listed in more detail.

\section{Results}

The survey conducted among farmers and companies revealed the following:

\begin{tabular}{lc}
\hline Type of abnormality reported & $\begin{array}{c}\text { Percentage } \\
\text { of purchased }\end{array}$ \\
\hline Variegation of leaves & 0.005 \\
Seedless fruit & 0.1 \\
Broader leaves and different & 1.4 \\
spine structure & \\
$\begin{array}{l}\text { No pollination in Barhee } \\
\text { variety, various degrees up to }\end{array}$ & 100 \\
$\begin{array}{l}\text { Bending of stem } \\
\text { Compact growth, broad }\end{array}$ & 1.5 \\
leaves & 4 \\
\hline
\end{tabular}

i) Variegation

The variegation of leaves was initially seen in the greenhouse. Among 100,000 plants produced, only 5 showed distinct variegation. Unlike general yellowing of the leaves caused by iron deficiencies, the leaves had a cream-coloured stripe running parallel to the leaf margin. The variegation occurred on all leaves but varied in stripe width. Otherwise healthy and green, growth rate of these plants differed from normal plants. Variegation as an off-type is common among other culture derived plants such as bananas (Robinson, 1996). Since environment (water, media and nutrition) was no different from other plants produced, other explanations for such abnormalities have to be sought, including virus/microbial contamination, in vitro media nutrient deficiency or genetic variation. 
ii) Seedless-fruit palm

The "seedless-fruit" palm produced dates small in size, but very sweet to taste. The palm was also different in appearance from the other neighbouring Medjool plants (Figure 1). Fruits will be reassessed in subsegment growing seasons to see whether this seedless phenomenon is repeated. As is well known, unfertilized fruit have no mature seed. Since the "seedless-fruit" date palm was a single plant among 1000 indentical Medjool plants in a plantation, a simple explanation for this abnormality might be that labels during delivery could have been mixed up and that this palm belongs toa different variety. However, there is no knowledge of any "seedlessfruit" variety being introduced to South Africa at any time. The palm also did not produce any off-shoots, unlike most other date palms.

\section{iii) Leaf structure and compact growth}

Medjool plants in the Northern Province of South Africa showed also variation in general appearance by having broader leaves and a different spine structure when compared to the rest of the plantation. The plants did produce fruit. A report from Namibia revealed that various plants labeled as Medjool were different in appearance once planted. The plants grew in a compact form with broader leaves (Figure 2) when compared to the majority of the other Medjool plants. The plants showing such abnormalities are scattered among other plants in various plantations. What is of interest is that the abnormalities have occurred only in Medjool. furthermore these plants were produced from three separate tissue culture laboratories all using somatic embryogenesis as a technique to propagate the palms. As the plants were grown under different climatic conditions, with different soils and management practices, and from different sources of origin, it is possible to rule out environmental conditions as a reason for the abnormality.
This suggests that the off-type may be directly related to the production process via somatic embryogenesis.

iv) Pollination

Pollination and subsequent fruit set problems have also been reported with Barhee tissue culture plants at various locations. Pollination problems occurred during the first two years of date palm production were no different than other varieties on the same plantation, which were successfully pollinated. Possible explanations for this different growth pattern are a delayed flowering time related to establishment and size when compared to offshoots, or a prolific vegetative growth as a result of juvenile vigour. High NPK (nitrogen, phosphate and potassium) input may have upset the balance required between vegetative and reproductive phases. Drought, cold weather and insufficient microelement application of Copper, Zinc and Boron might also have contributed as factors on pistil development and fruit set. However, somaclonal variation might also be a possibility for this off-type appearance. Interestingly, these plants originated from a tissue culture method of proliferating embryos and not callus and no 2,4-D is reported to have been used in the process of establishment.

For oil palm, three different types of abnormal development were reported, two of them concerning the sex of the flowers (Corley, et al., 1986). One of the possible causes for variation considered is somaclonal variation induced in callus cultures. The use of 2,4-D in the medium may have increased the frequency of somaclonal variation, but two of the clones showing the abnormalities had never been cultured on 2,4-D (Corley, et al., 1986). Somaclonal variation normally occurs at the callus stage, but the abnormalities reported (e.g. mantled fruit) were from palms reproduced not from callus, but continuous culture. This appears to be similar to the results found in date palm.

v) Stem bending 
A number of different farmers reported a bending of the palm stem. The bending did not always occur in the same direction. The bending of the palm stem was investigated further and found to have symptoms of Black scorch disease (Figure 3) caused by the fungus Thievaliopsis $s p$. It appears that the tissue culture plants are more susceptible to this phenomenon than those plants introduced from off-shoots in South Africa.

\section{vi) In vitro abnormalities}

In addition to the off-types found in the plantations survey, variations observed on in vitro plants included:

- Dwarfs (thick plants with short succulent leaves that expand),

- unproportionate shoot:root ratio

- sheath restriction on leaf emergence and

- 'Blind' meristems where the shoot meristem appears to be blocked or restricted (this phenomenon occurs in all techniques used).

\section{Discussion}

This study conducted in Southern Africa shows that growth variations do occur from tissue cultured plants produced by somatic embryogenesis (direct and indirect). The frequency, with the exception of the Barhee pollination problem, is low (less than $5 \%$ ). Possible causes of abnormal development among tissue culture plants are:

\section{1) Environmental factors}

These include disease, nutrition and climate.

\section{2) Physiological factors}

Tissue culture plants grow at different rates to seedlings and off-shoots. The vegetative phase in tissue cultured plants is more pronounced due to juvenile vigour, possibly due to the build up of endogenous plant growth regulators after in vitro propagation. To reduce this effect, a better understanding is needed of cytokinin and auxin levels within the plant and at what level plant growth regulators are needed to induce the required response in vitro.

\section{3) Human error}

Mislabeling of plants has often caused much confusion and must also be taken into consideration. Inappropriate pollination, watering, fertilization and disease control practices also lead to variation in growth responses within a plantation.

\section{4) Tissue culture-somaclonal variation}

The type of plant growth regulator used such as 2,4-D and the concentration it is used at may contribute to somaclonal variation. Proliferation of shoots and embryos is generally considered to reduce the risk of variation when compared to undifferentiated material such as callus. The type of micropropagation method or process involved therefore also plays a role. Corley et al. (1986) suggests that the time for which the tissues are in culture may be an important factor in the abnormalities observed in oil palm plantations derived from the same population of cultures. Prolonged culture on media containing plant growth regulators may disrupt the normal hormone metabolism of the cells in some way. This disruption could persist in plants regenerated from the cultures, leading to developmental abnormalities. Such effects are known to occur with other plant species such as maize with gibberellic acid treatments (Rood et al., 1980). Lastly, the type of mother material or explant used may also play an important role in later developmental abnormalities. The mother plant must have a proven production record and originate from an orchard where sound management practices are exercised. Plantations where many unregistered herbicides, pesticides and fungicides are used should be avoided. 
The results demonstrate merely phenotypic characteristics and it will be necessary to determine the genetic variation by means of molecular technology. However, much work has to be done to determine the DNA sequences for the various critical characteristics in date palms. Although the variations reported concentrated on tissue cultured plants produced using somatic embryogenesis, the author cautions against any preference to plants produced by organogenesis until a thorough field investigation has been conducted.

Although much work has been done to develop tissue culture techniques on the mass production of date palms, more research is needed to verify the clonal nature of callus, embryo and organ- initiated plantlets produced in vitro. Date palm plantlets should be grown to maturity and the fruit quality and vegetative characteristics compared with the parental clone to determine their clonal status. Although this has been done by some tissue culture laboratories, the length of the process to establish cultures, produce the in vitro plantlets, establish the plants in the field and then evaluate the palms at maturity could take between 7-10 years. In addition, to maintain cultures in the laboratory for such a long period would be risky due to contamination problems. However, more frequent initiations producing fewer volumes of plants per mother plant should be considered by commercial producers as a strategy to reduce the risk on somaclonal variation.

"Mutations and sports produced through tissue culture plants should not be ignored (Tisserat, 1981). As variation affecting production can result in massive financial loss and bearing in mind that the date palm is a long-term investment, it is to be taken seriously. Lastly, it is important that not all variability is to be regarded as a negative artifact of tissue culture, but instead, to be seen as a new source of traits and information for plant improvement.

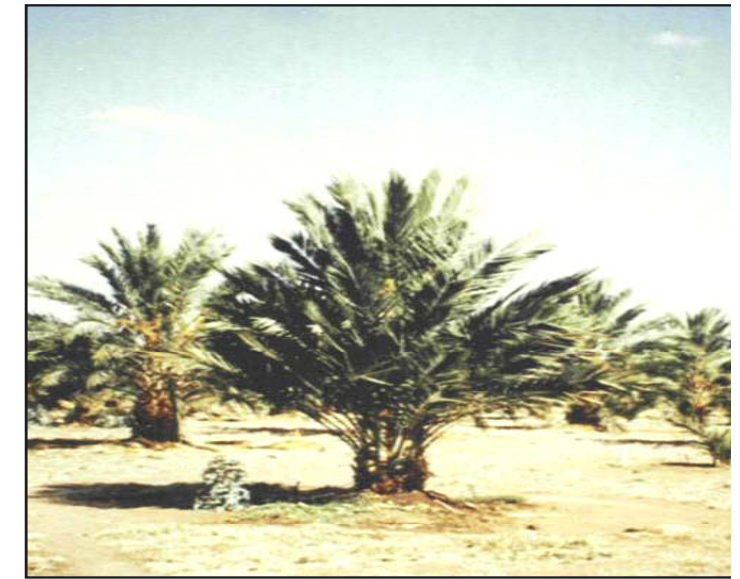

Figure 1. Date palm that produces seedless fruits showing a different growth pattern to the rest of

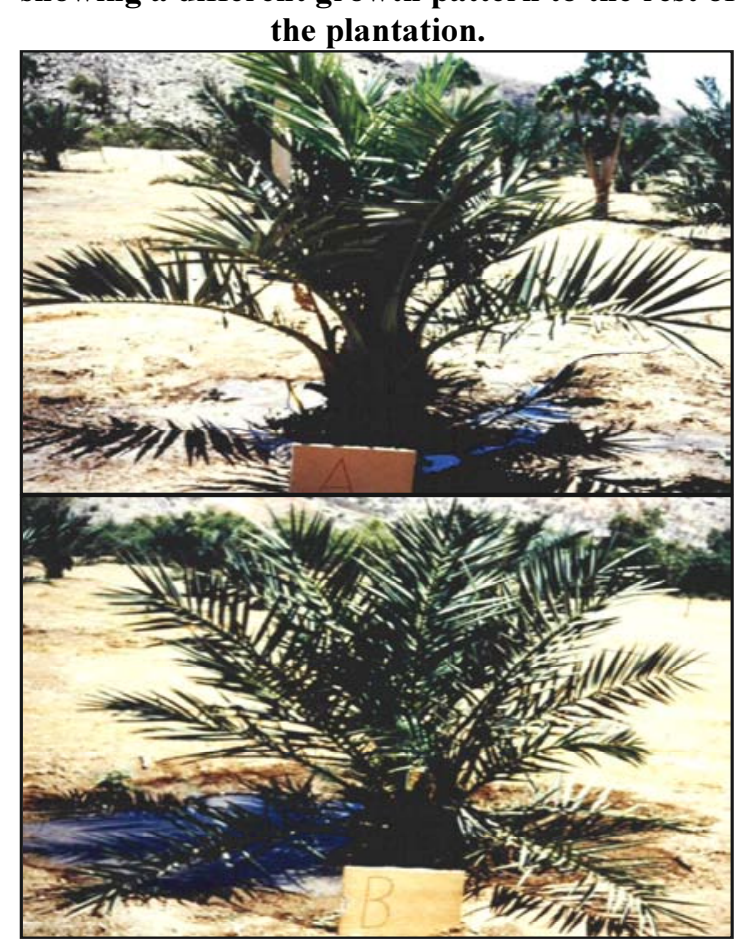

Figure 2. Off-type date palm of the variety Medjool (A) showing broader leaves and a more compact growth habit than a true-to-type Medjool plant (B).

\section{References}

Al-Shayji, Y. M. Shaleem, S. Al-Amad, S. Al-Awadhi, and F. Al-Salameen, 1994. Isolation and analysis of the total genomic DNA from the date palm $(P$. dactylifera L.) and related species. Acta Biotechnol. 14 (2): 163-168. 
Emir. J. Agric. Sci. 2004. 16 (1) : 08-14

http://www.cfs.uaeu.ac.ae/research/ejas.html

Corley, R. H. V., C. H. Lee, I. H. Law, and C. Y. Wong. 1986. Abnormal flower development in oil palm clones. Planter, Kuala Lumpur 62: 233-240

Corniquel, B. and L. Mercier. 1994. Date palm (Phoenix dactylifera L.) cultivar identification by RFLP and RAPD. Plant Science 101: 163-172.

Evans, D. 1989. Somaclonal variationgenetic basis and breeding applications. Trends Genet. 5: 46-50.

Miller, J. A. 1985. Harvest of an agronomic anomaly. Science News 128: 120:121.

Loubser, J. W. 1980. Die invloed van 2,4-D -bespuitings of die ontwikkeling, groei en gevoeligheid van clippergars. Ph.D. thesis, University of Stellenbosch, RSA.

Paranjothy, K. 1982. A review of tissue culture of oil palm and other palms, PORIM occasional paper 3: 1-22.

Terzi, M. and F. Loschiavo 1990. Progress in Plant Cellular and Molecular Biology, In H. J. J. Nijkamp, L. H. W. Van der Plas and J. Van Aartrijk (Eds). pp. 391-397.

Tisserat, B. 1981. Production of free-living date palms through tissue culture, Date Palm J. 1(1): 43-54.

Robinson, J. C. 1996. Bananas and plantains, Crop production science in Horticulture No. 5, Atherton, J. and Rees, A. (eds), p 108. 